\title{
Radial Artery of the Upper Extremity
}

National Cancer Institute

\section{Source}

National Cancer Institute. Radial Artery of the Upper Extremity. NCI Thesaurus. Code C34012.

An artery arising from the brachial artery just below the bend of the elbow with numerous branches in the forearm, wrist and hand. 